\title{
Correction: Lactate dehydrogenase A inhibition by small molecular entities: steps in the right direction
}

\author{
Btissame El Hassouni ${ }^{1}$, Marika Franczak ${ }^{2}$, Mjriam Capula ${ }^{3}$, Christian M. Vonk ${ }^{1}$, \\ Valentina M. Gomez ${ }^{1}$, Ryszard T. Smolenski ${ }^{2}$, Carlotta Granchi ${ }^{4}$, Godefridus J. \\ Peters ${ }^{1,2}$, Filippo Minutolo ${ }^{4}$, Elisa Giovannetti ${ }^{1,3}$ \\ ${ }^{1}$ Department of Medical Oncology, Amsterdam UMC, VU University Medical Center, Amsterdam, Netherlands \\ 2 Department of Biochemistry, Medical University of Gdansk, Gdansk, Poland \\ ${ }^{3}$ Fondazione Pisana per la Scienza, Pisa, Italy \\ ${ }^{4}$ Dipartimento di Farmacia, Università di Pisa, Pisa, Italy
}

Correspondence to: Elisa Giovannetti, email: e.giovannetti@amsterdamumc.nl

Published: March 30, 2021

Copyright: @ $2021 \mathrm{El}$ Hassouni et al. This is an open access article distributed under the terms of the Creative Commons Attribution License (CC BY 3.0), which permits unrestricted use, distribution, and reproduction in any medium, provided the original author and source are credited.

Original article: Oncoscience. 2020 Sep 9;7(9-10):76-80

PMCID: PMC7640902 PMID: 33195739

DOI: $10.18632 /$ oncoscience. 519

This article has been corrected: In Figure 3C, the graph is mislabeled. The correct unit of measurement, $\mu \mathrm{M}$, is shown in the figure below. The authors declare that these corrections do not change the results or conclusions of this paper.

A

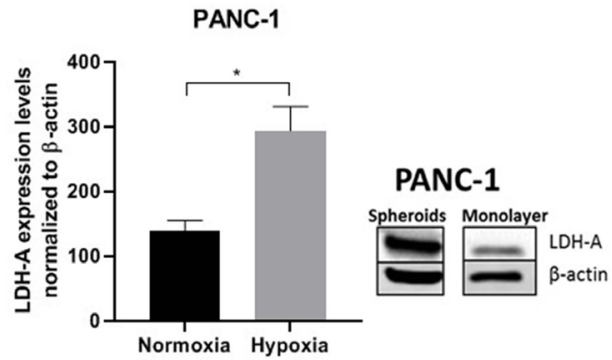

C

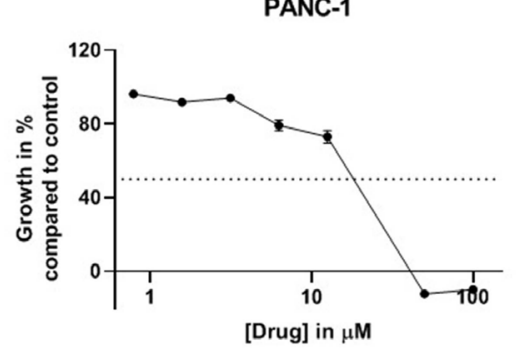

B

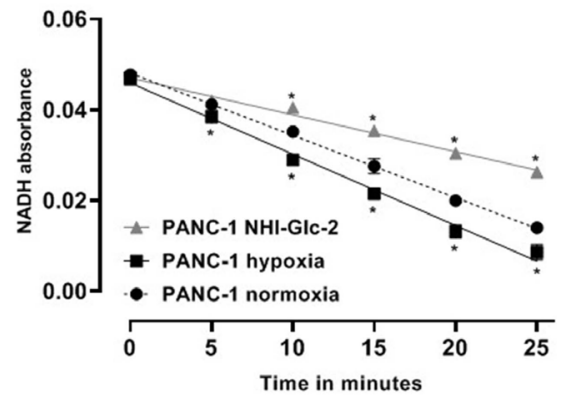

D

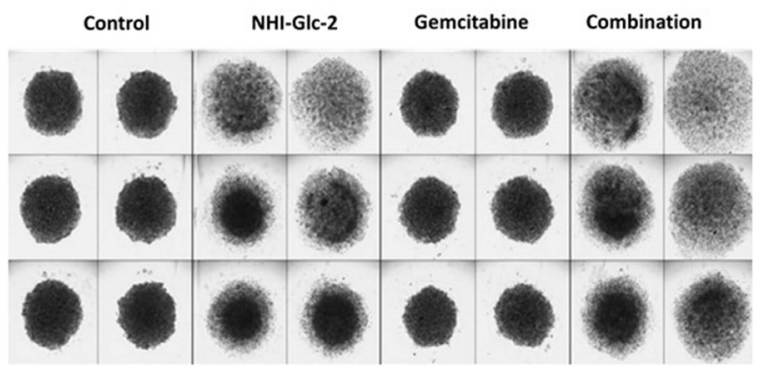

